\title{
Bolus Administration of Intravenous Glucose in the Treatment of Hyperkalemia: A Randomized Controlled Trial
}

\author{
Mogamat-Yazied Chothia ${ }^{a}$ Mitchell L. Halperin ${ }^{d, e}$ Megan A. Rensburg ${ }^{b}$ \\ Mogamat Shafick Hassan ${ }^{c}$ Mogamat Razeen Davids ${ }^{a}$
}

\begin{abstract}
${ }^{a}$ Division of Nephrology, Department of Medicine, Stellenbosch University and Tygerberg Hospital, ${ }^{b}$ Division of Chemical Pathology, National Health Laboratory Service and Stellenbosch University, and ${ }^{\mathrm{C}}$ Faculty of Health and Wellness Science, Cape Peninsula University of Technology, Cape Town, South Africa; 'Division of Nephrology, University of Toronto, and ${ }^{\mathrm{K}}$ Keenan Research Building, Li Ka Shing Knowledge Institute of St. Michaels Hospital, Toronto, Ont., Canada
\end{abstract}

\section{Key Words}

Clinical trial · Glucose · Hyperkalemia · Hypoglycemia · Insulin

\footnotetext{
Abstract

Background: Hyperkalemia is a common medical emergency that may result in serious cardiac arrhythmias. Standard therapy with insulin plus glucose reliably lowers the serum potassium concentration ([K+]) but carries the risk of hypoglycemia. This study examined whether an intravenous glucose-only bolus lowers serum $\left[\mathrm{K}^{+}\right]$in stable, nondiabetic, hyperkalemic patients and compared this intervention with insulin-plus-glucose therapy. Methods: A randomized, crossover study was conducted in 10 chronic hemodialysis patients who were prone to hyperkalemia. Administration of 10 units of insulin with $100 \mathrm{ml}$ of $50 \%$ glucose $(50 \mathrm{~g})$ was compared with the administration of $100 \mathrm{ml}$ of $50 \%$ glucose only. Serum $\left[\mathrm{K}^{+}\right]$was measured up to $60 \mathrm{~min}$. Patients were monitored for hypoglycemia and EKG changes. Results: Baseline serum $\left[\mathrm{K}^{+}\right]$was $6.01 \pm 0.87$ and $6.23 \pm 1.20 \mathrm{mmol} / \mathrm{l}$ in the insulin and glucose-only groups, respectively $(p=$ $0.45)$. At $60 \mathrm{~min}$, the glucose-only group had a fall in $\left[\mathrm{K}^{+}\right]$of $0.50 \pm 0.31 \mathrm{mmol} / \mathrm{l}(p<0.001)$. In the insulin group, there was a fall of $0.83 \pm 0.53 \mathrm{mmol} / \mathrm{l}$ at $60 \mathrm{~min}(p<0.001)$ and a lower
}

serum $\left[\mathrm{K}^{+}\right]$at that time compared to the glucose-only group $(5.18 \pm 0.76$ vs. $5.73 \pm 1.12 \mathrm{mmol} / \mathrm{l}$, respectively; $p=0.01)$. In the glucose-only group, the glucose area under the curve (AUC) was greater and the insulin AUC was smaller. Two patients in the insulin group developed hypoglycemia. Conclusion: Infusion of a glucose-only bolus caused a clinically significant decrease in serum $\left[\mathrm{K}^{+}\right]$without any episodes of hypoglycemia.

\section{Introduction}

Hyperkalemia is a frequently encountered medical emergency that can lead to life-threatening cardiac arrhythmias and therefore requires rapid and effective treatment. In hospitalized patients, hyperkalemia is often seen in individuals who are older, have impaired renal function, or are being treated with potassium supplementation or drugs which block the renin-angiotensin-aldosterone system $[1,2]$. The principles of management involve protecting the heart, shifting potassium into cells, eliminating potassium from the body and treating the underlying causes of the hyperkalemia. 
Several aspects of the emergency treatment remain controversial, although regular (soluble) insulin plus glucose is usually recommended as first-line therapy in the acute management. $\beta_{2}$-Agonists may lower serum potassium $\left(\mathrm{K}^{+}\right)$to a similar degree as insulin, but around one third of patients have a decline in serum $\mathrm{K}^{+}$that is $<0.5$ $\mathrm{mmol} / \mathrm{l}$, and therefore using these agents as monotherapy is not recommended [3]. The doses of $\beta_{2}$-agonists required to lower serum $\mathrm{K}^{+}$are severalfold higher than those used in acute asthma, leading to safety concerns, especially in patients who may also have cardiac disease. Sodium bicarbonate is recommended in the acute setting only if associated with a severe degree of acidosis [4]. Cation exchange resins do not significantly increase potassium excretion in the acute setting $[5,6]$ and have been associated with instances of colonic necrosis when used in combination with sorbitol [7-9]. They can therefore no longer be considered to be part of the standard treatment for acute hyperkalemia $[3,10,11]$.

Insulin causes a shift in $\mathrm{K}^{+}$into cells by activating NHE1 , the $\mathrm{Na}^{+} / \mathrm{H}^{+}$exchanger, in cell membranes [12]. The subsequent entry of $\mathrm{Na}^{+}$into the cell activates $\mathrm{Na}^{+} / \mathrm{K}^{+}$ATPase, which causes the exit of $3 \mathrm{Na}^{+}$and the entry of $2 \mathrm{~K}^{+}$with each cycle of the pump. In this way, insulin therapy rapidly and reliably lowers serum $\left[\mathrm{K}^{+}\right]$, but this comes at the cost of frequent episodes of hypoglycemia, even when glucose is given concurrently to try and prevent this complication [13-16]. Hypoglycemia is a serious and common adverse effect of insulin therapy and may manifest several hours after insulin administration $[17,18]$.

While earlier studies in various settings have demonstrated that oral or intravenous glucose loading can lower serum $\left[\mathrm{K}^{+}\right][19-22]$, this has never been adopted as a component of the therapy for the emergency treatment of hyperkalemia. There have been concerns that the administration of an intravenous glucose bolus without insulin might not elicit sufficient release of endogenous insulin to cause a rapid, reliable and clinically useful degree of potassium shift into cells $[3,23,24]$. Some uremic patients may have a decreased early insulin response [25], and acutely ill patients may have $\alpha$-adrenergic activation causing impaired pancreatic insulin release [26]. Another concern is that the administration of hypertonic glucose may paradoxically worsen the hyperkalemia by causing a shift of potassium out of cells [27-29]. Solvent drag of potassium-rich intracellular water into the extracellular compartment and increased leakage of potassium out of cells effected by the hypertonicity have been suggested as possible mechanisms for this phenomenon [29].
We studied the question of shifting potassium into cells in a group of hyperkalemic patients on chronic hemodialysis (HD) and compared the efficacy and safety of a glucose bolus with that of standard insulin-glucose therapy. Many of the studies which have informed the current treatment of hyperkalemia have been conducted in similar groups of patients with end-stage renal disease (ESRD). While these patients all have some degree of insulin resistance with respect to glucose homeostasis [30-32], the other actions of insulin are maintained, including the shift of potassium into cells [33].

\section{Materials and Methods}

We undertook this clinical trial in ESRD patients who were on thrice-weekly HD at the Renal Unit of Tygerberg Hospital in Cape Town, South Africa. Ethics approval was obtained from the Stellenbosch University Health Research Ethics Committee (reference No. M07/10/060). All participants gave written, informed consent. The trial adhered to the Declaration of Helsinki and was registered in the Pan African Clinical Trials registry before commencement (reference No. ATMR2009100001631792).

\section{Participants}

The study population of 10 individuals was recruited from stable nondiabetic patients who had been on chronic HD for at least 3 months. Participants prone to developing hyperkalemia were identified from their last 3 sets of routine blood results, with all having serum $\left[\mathrm{K}^{+}\right]$exceeding $5.0 \mathrm{mmol} / \mathrm{l}$ before dialysis in each of the tests.

\section{Study Design}

A randomized, crossover, double-blind study was conducted with a washout period of at least 1 week between the two interventions for each participant (fig. 1). Simple randomization to receive insulin plus glucose or the glucose-only bolus as the first treatment was done using a computer-generated random number sequence. Allocation concealment was achieved with the use of sequentially numbered, opaque, sealed envelopes. An independent assistant prepared syringes with either 10 units of regular insulin or with an equivalent volume of saline. The participants, the treating doctor and the dialysis staff were blinded to the treatment administered.

\section{Study Procedures}

Participants were all studied in the non-fasting state on dialysis days following their longest interdialytic period. All blood samples were drawn from a cannulated arteriovenous fistula or a temporary dialysis catheter, were centrifuged promptly and processed by a single, internationally accredited laboratory. Potassium concentrations were measured by ion-selective electrode, glucose was measured by the hexokinase method and insulin by immunoassay on Roche/Hitachi Cobas ${ }^{\circledR}$ c 501 and c 601 systems. Baseline samples for potassium, glucose and insulin levels were taken. Blood pressure, heart rate and weight were documented, and a 12-lead EKG tracing recorded. The insulin, and the saline in the case of the controls, was injected into a $50-\mathrm{ml}$ bag of $50 \%$ dextrose and infused rapidly at time 0 . This was followed immediately by the infusion of a second $50-\mathrm{ml}$ 


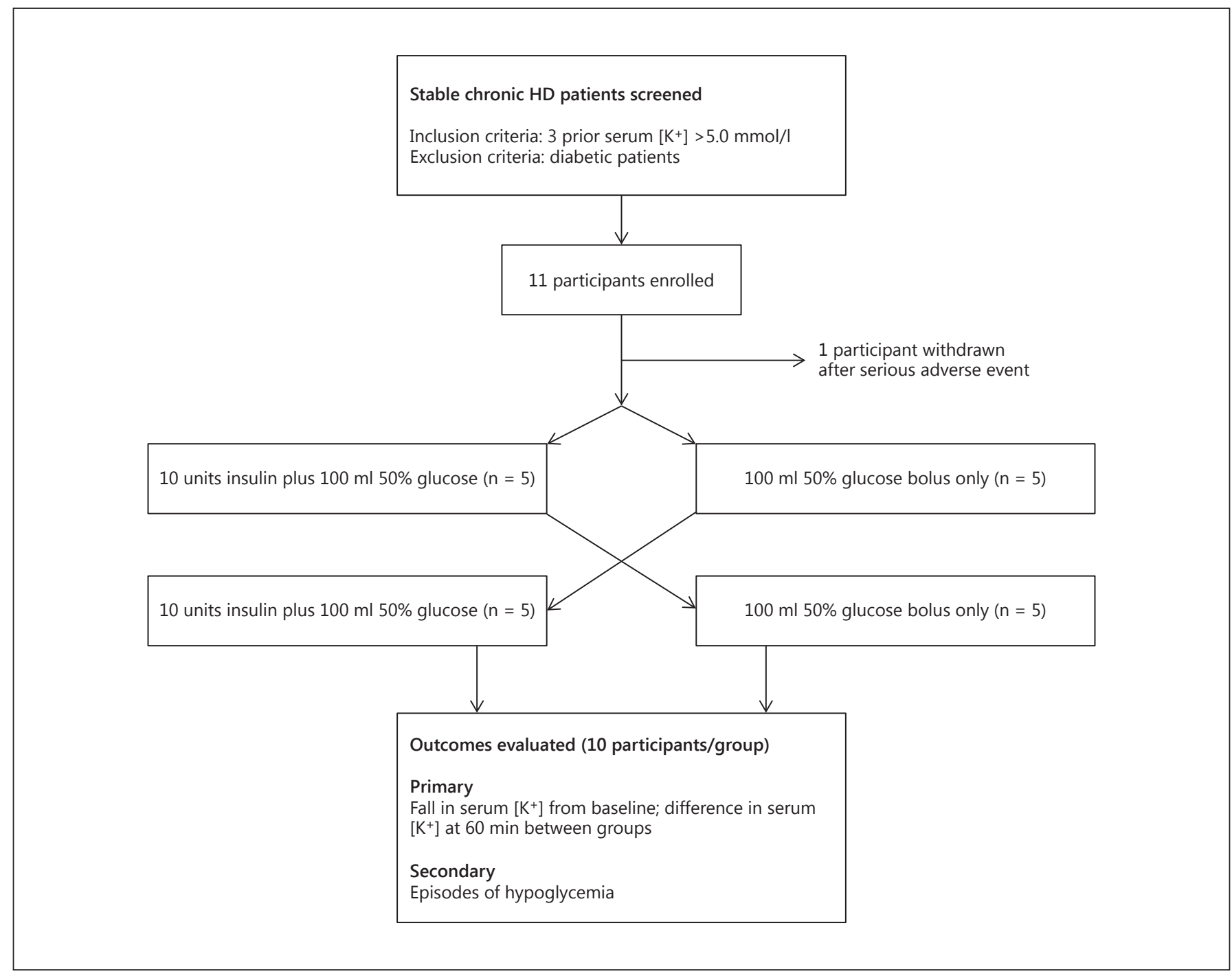

Fig. 1. Study flow diagram: in this crossover design, 10 participants completed both arms of the study and could be evaluated. The first treatment for each participant was randomly assigned, and participants and medical staff were blinded to the treatment administered. Each participant had a washout period of at least 1 week between treatment arms.

bag of $50 \%$ dextrose and then by $50 \mathrm{ml}$ of normal saline to flush the giving set. The total dose of glucose administered was $50 \mathrm{~g}$ and the infusion of the solutions took 4-5 min. Blood samples for potassium, glucose and insulin levels were repeated after 10, 20, 40 and 60 min. Blood pressure and heart rate measurements were repeated at the same time points. Bedside blood glucose measurements were done at each time point using a Roche Accu-Chek Active ${ }^{\circledR}$ glucometer and participants were monitored for symptoms of hypoglycemia. If blood glucose fell $<3.0 \mathrm{mmol} / \mathrm{l}$ or symptoms of hypoglycemia developed at any point, an additional $50-\mathrm{ml}$ bolus of $50 \%$ dextrose was infused. The EKG was repeated after $60 \mathrm{~min}$. EKGs were read by two of the authors (M.-Y.C. and M.R.D.) to identify changes typical of hyperkalemia, namely tall, peaked $\mathrm{T}$ waves, flattened or $\mathrm{ab}$ sent $\mathrm{P}$ waves and widening of the QRS complex.

\section{Outcomes}

The primary outcomes of interest were the magnitude of the fall in serum $\left[\mathrm{K}^{+}\right]$from baseline values and the difference in serum $\left[\mathrm{K}^{+}\right]$at $60 \mathrm{~min}$ between the two treatment groups. The secondary outcomes related to safety, namely episodes of hypoglycemia and EKG abnormalities.

\section{Statistical Methods}

Data are reported as means \pm SD and statistical significance was set at $\mathrm{p}<0.05$. 


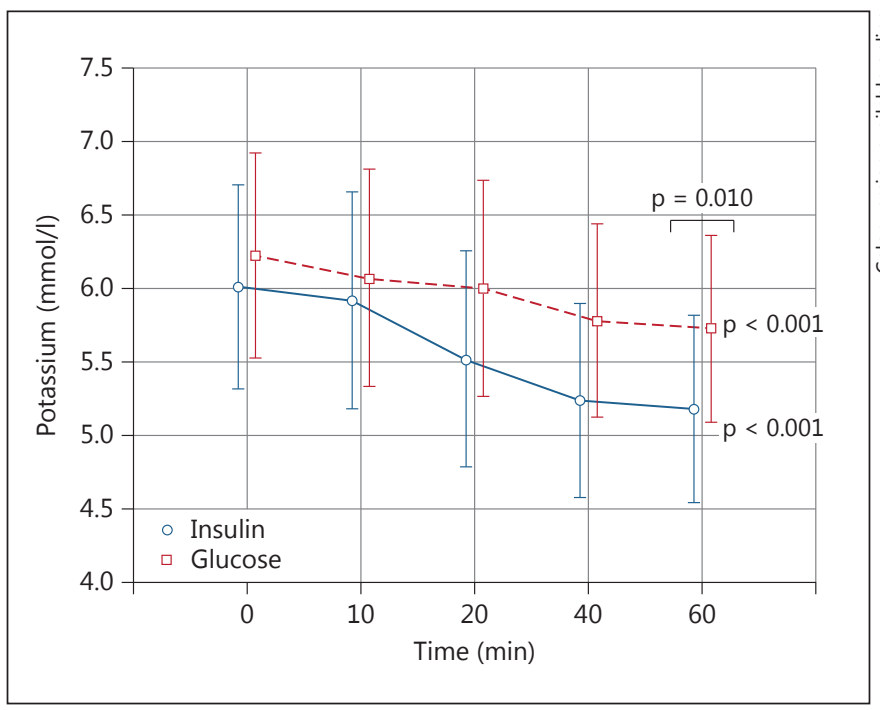

Fig. 2. Serum potassium concentration versus time: values at 60 min are significantly lower than baseline values in each treatment group ( $\mathrm{p}<0.001$ in each case); at 60 min they are significantly lower in the insulin as compared to the glucose-only group ( $\mathrm{p}=$ $0.010)$. Mean values with $95 \%$ confidence intervals.

Table 1. Baseline characteristics of the participants $(n=10)$

\begin{tabular}{lccl}
\hline Baseline characteristics & $\begin{array}{l}\text { Insulin- } \\
\text { glucose }\end{array}$ & $\begin{array}{l}\text { Glucose- } \\
\text { only }\end{array}$ & $\begin{array}{l}\mathrm{p} \\
\text { values }\end{array}$ \\
\hline Males, $\mathrm{n}$ & 5 & 5 & \\
Mean age, years & 40.2 & 40.2 & \\
Mean potassium, mmol/l & $6.01 \pm 0.87$ & $6.23 \pm 1.20$ & 0.45 \\
Mean glucose, $\mathrm{mmol} / \mathrm{l}$ & $5.57 \pm 2.01$ & $5.08 \pm 0.73$ & 0.50 \\
Mean insulin, $\mu \mathrm{U} / \mathrm{ml}$ & $28.41 \pm 32.7$ & $21.84 \pm 18.3$ & 0.48 \\
\hline
\end{tabular}

\section{Results}

The baseline characteristics of the participants are summarized in table 1 . The 10 participants who completed the study had a mean age of 40.2 years (range 20-54). There were equal numbers of males and females. There were 6 participants who were being treated with atenolol for hypertension during the study.

At baseline, the mean serum $\left[\mathrm{K}^{+}\right]$was $6.01 \pm 0.87$ $\mathrm{mmol} / \mathrm{l}$ in the insulin group and $6.23 \pm 1.20 \mathrm{mmol} / \mathrm{l}$ in the glucose-only group $(\mathrm{p}=0.449)$. At $60 \mathrm{~min}$, the glucoseonly group had a fall in $\left[\mathrm{K}^{+}\right]$of $0.50 \pm 0.31 \mathrm{mmol} / \mathrm{l}(\mathrm{p}<$ 0.001 ) while in the insulin group there was a fall from baseline of $0.83 \pm 0.53 \mathrm{mmol} / \mathrm{l}(\mathrm{p}<0.001)$. The insulin

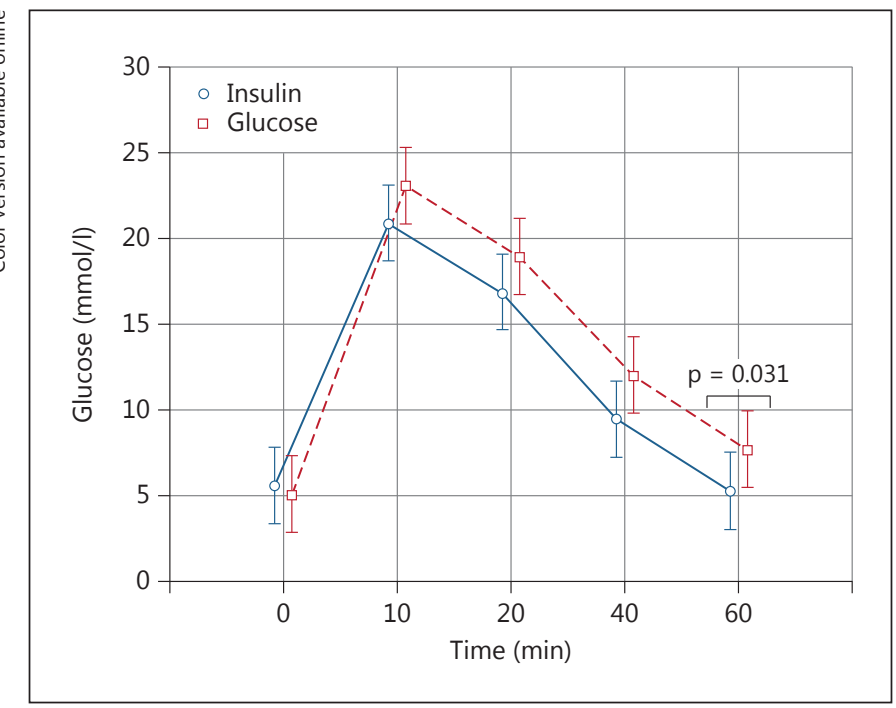

Fig. 3. Plasma glucose concentration versus time: at $60 \mathrm{~min}$, but not at any other time point, the glucose concentrations were higher in the glucose-only group (7.68 vs. $5.26 \mathrm{mmol} / \mathrm{l}, \mathrm{p}=0.031$ ). Mean values with $95 \%$ confidence intervals.

group had a lower serum $\left[\mathrm{K}^{+}\right]$at $60 \mathrm{~min}$ as compared to the glucose-only group $(5.18 \pm 0.76 \mathrm{vs} .5 .73 \pm 1.12 \mathrm{mmol} / \mathrm{l}$, respectively; $\mathrm{p}<0.010$; fig. 2 ).

There was no difference in the fall in mean serum $\left[\mathrm{K}^{+}\right]$ at $60 \mathrm{~min}$ between participants who were on atenolol as compared with those who were not ( $0.66 \mathrm{vs.} 0.60 \mathrm{mmol} / \mathrm{l}$, respectively; $\mathrm{p}=0.645$ ).

Analysis of individual patient data revealed that 9 of the 10 participants in the glucose-only group had a fall in serum $\left[\mathrm{K}^{+}\right]$at $60 \mathrm{~min}$ while 1 participant was unchanged (the fall from baseline values ranged from 0.0 to 1.1 $\mathrm{mmol} / \mathrm{l})$. All the participants in the insulin group had a lower value at $60 \mathrm{~min}$ (differences ranged from 0.1 to 2.0 $\mathrm{mmol} / \mathrm{l})$. At the earliest time point $(10 \mathrm{~min})$, there was 1 participant in the glucose group with a higher serum $\left[\mathrm{K}^{+}\right]$ than at baseline (an increase of $0.2 \mathrm{mmol} / \mathrm{l}$ ), while there were 3 participants with a rise in serum $\left[\mathrm{K}^{+}\right]$at this time point (mean increase of $0.4 \mathrm{mmol} / \mathrm{l}$ ) in the insulin group.

Plasma glucose concentrations (fig. 3) were similar at baseline in the insulin and glucose-only groups (5.57 \pm 2.01 vs. $5.08 \pm 0.73 \mathrm{mmol} / \mathrm{l}$, respectively; $\mathrm{p}=0.500)$. Glucose concentrations at $60 \mathrm{~min}$ were higher in the glucoseonly group ( $5.26 \mathrm{vs} .7 .68 \mathrm{mmol} / \mathrm{l} ; \mathrm{p}=0.031$ ) but not at the earlier time points. The area under the curve (AUC) was greater in the glucose-only group with a mean AUC of $857.8 \pm 54.2$ versus $731.0 \pm 59.0 \mathrm{mmol} \cdot \mathrm{min} / \mathrm{l}(\mathrm{p}=0.048)$. 


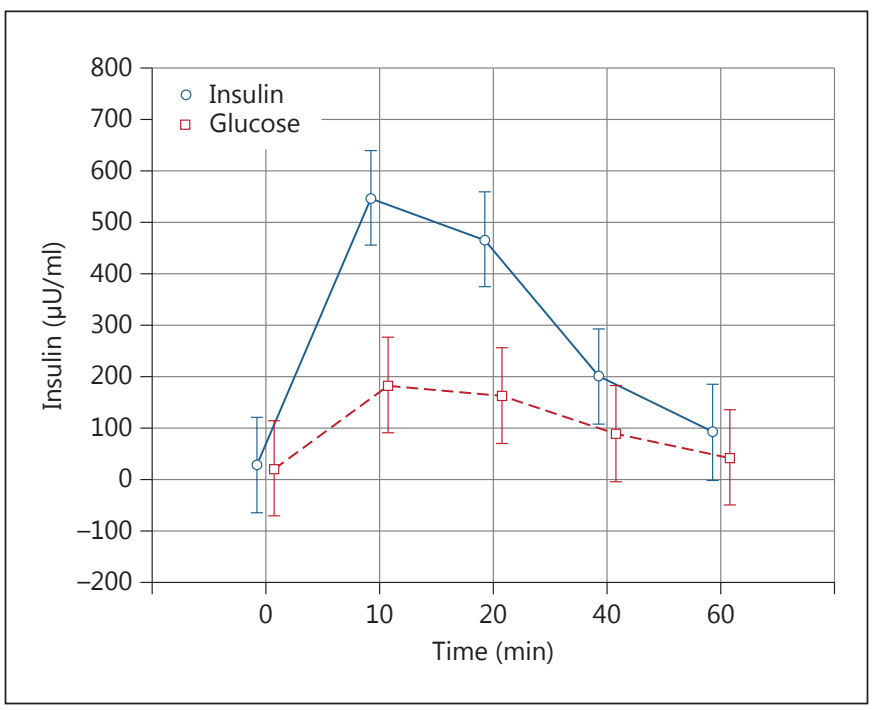

Fig.4. Serum insulin concentration versus time: insulin concentrations were similar at baseline in both groups $(p=0.484)$ but were higher in the insulin group at $10(\mathrm{p}=0.002), 20(\mathrm{p}<0.001), 40$ $(\mathrm{p}=0.034)$ and $60 \mathrm{~min}(\mathrm{p}=0.038)$. The mean AUC was greater in the insulin group $(17,564.1$ vs. $6,626.3 \mu \mathrm{U} \cdot \mathrm{min} / \mathrm{ml}, \mathrm{p}=0.001)$. Mean values with $95 \%$ confidence intervals.

Insulin concentrations (fig. 4) were similar at baseline $(28.4 \pm 32.7 \mu \mathrm{U} / \mathrm{ml}$ in the insulin group vs. $21.8 \pm 18.3 \mu \mathrm{U} /$ $\mathrm{ml}$ in the glucose-only group, $\mathrm{p}=0.484$ ) but higher at 10 $\min (547.5 \pm 348.5$ vs. $183.7 \pm 128.2 \mu \mathrm{U} / \mathrm{ml}, \mathrm{p}=0.002), 20$ $\min (467.4 \pm 217.0$ vs. $163.4 \pm 99.6 \mu \mathrm{U} / \mathrm{ml}, \mathrm{p}<0.001), 40$ $\min (200.6 \pm 145.0$ vs. $89.7 \pm 40.0 \mu \mathrm{U} / \mathrm{ml}, \mathrm{p}=0.034)$ and at $60 \mathrm{~min}(92.3 \pm 66.1$ vs. $43.5 \pm 23.4 \mu \mathrm{U} / \mathrm{ml}, \mathrm{p}=0.038)$ in the insulin group. The AUC was greater in the insulin group with a mean AUC of 17,564.1 $\pm 2,897.1$ versus $6,626.3 \pm 1,129.9 \mu \mathrm{U} \cdot \mathrm{min} / \mathrm{ml}(\mathrm{p}=0.001)$.

Two participants in the insulin group developed hypoglycemia. Both were using atenolol. One developed symptomatic hypoglycemia with a glucose concentration of 2.4 $\mathrm{mmol} / \mathrm{l}$ at $90 \mathrm{~min}$ and the other developed asymptomatic hypoglycemia with a glucose concentration of $1.4 \mathrm{mmol} / \mathrm{l}$ at $60 \mathrm{~min}$. They received an additional $50 \mathrm{ml}$ of $50 \%$ glucose as per protocol. There were no episodes of hypoglycemia in the glucose-only group.

One participant developed pulmonary edema shortly after the administration of the study medication (insulin plus glucose). EKG and cardiac enzymes did not reveal any evidence of arrhythmia, ischemia or infarction, but echocardiography revealed hypertensive heart disease with severe diastolic dysfunction. The participant was withdrawn from the study after this serious adverse event.
All patients reported a warm or burning sensation at the site of infusion, which subsided as soon as the infusion ended.

In 5 patients, EKG changes of hyperkalemia were present at baseline on both arms of the study and in 1 patient on the occasion of the glucose arm only. Tall $\mathrm{T}$ waves were present in all of these cases, and decreases in $\mathrm{T}$ wave amplitude were observed on the 60 -min EKG in all the patients after insulin administration and in 3 of the 6 patients after administration of the glucose-only bolus. A flat $\mathrm{P}$ wave was present in 1 patient before the glucose-only bolus; this was unchanged at $60 \mathrm{~min}$. No widening of the QRS complexes was seen.

\section{Discussion}

In our study, an intravenous glucose bolus caused a clinically significant decrease in serum $\left[\mathrm{K}^{+}\right]$concentration of approximately $0.5 \mathrm{mmol} / \mathrm{l}$, without any incidents of hypoglycemia. These findings suggest that an intravenous infusion of glucose could be considered as a therapeutic option in the emergency treatment of hyperkalemia in settings where careful monitoring for hypoglycemia may not always be possible and where attending clinicians may prefer to avoid the risk of this serious complication altogether.

This approach of using endogenously secreted insulin to shift $\mathrm{K}^{+}$into cells is supported by data from a recent paper by Cheema-Dhadli et al. [34], who studied the effects of an infusion of L-lactic acid on $\mathrm{K}^{+}$shift in rats. They demonstrated that the liver plays a major role in removing absorbed dietary $\mathrm{K}^{+}$from the portal blood, thereby minimizing the risk of cardiac arrhythmia which might result if blood with a high serum $\mathrm{K}^{+}$concentration were delivered to the heart. The first component of the proposed mechanism is a high rate of production of L-lactic acid by enterocytes with subsequent lactic acid entry into hepatocytes on the monocarboxylic acid cotransporter [35]. The second is the release of insulin into the portal vein in response to a rise in blood glucose concentrations. These factors activate NHE-1 [36] and allow the entry of $\mathrm{Na}^{+}$followed by its electrogenic efflux via $\mathrm{Na}^{+}-\mathrm{K}^{+}-$ ATPase, creating a more negative intracellular voltage and retaining more $\mathrm{K}^{+}$inside hepatocytes.

Our participants receiving insulin had higher insulin concentrations and a larger fall in serum $\mathrm{K}^{+}$concentration compared to those receiving glucose only. In future studies, it would be useful to study the effects of infusing larger doses of glucose to try and induce more endogenous insulin release and possibly achieve a fall in $\mathrm{K}^{+}$con- 
Table 2. Risk of hypoglycemia with insulin therapy for hyperkalemia

\begin{tabular}{|c|c|c|c|c|c|c|}
\hline Study and participants (n) & $\begin{array}{l}\text { Glucose, } \\
\mathrm{g}\end{array}$ & $\begin{array}{l}\text { Insulin, } \\
\text { units }\end{array}$ & $\begin{array}{l}\text { Glu/Ins } \\
\text { ratio }\end{array}$ & $\begin{array}{l}\text { Hypoglycemia, } \\
\mathrm{n}(\%)\end{array}$ & $\Delta \mathrm{K}^{+}$ & Details \\
\hline $\begin{array}{l}\text { Blumberg et al. [13] } 1988 \\
\text { ESRD (10) }\end{array}$ & 20 & 20 & 1 & $5(50)$ & 0.92 & $\begin{array}{l}\text { Insulin-glucose infusion at } 5 \mathrm{mU} / \mathrm{kg} / \mathrm{min} \\
\text { insulin for } 60 \mathrm{~min}\end{array}$ \\
\hline $\begin{array}{l}\text { Lens et al. [14] } 1989 \\
\text { ESRD/AKI (10) }\end{array}$ & 40 & 10 & 4 & $2(20)$ & 1.0 & Glucose over $15 \mathrm{~min}$ and insulin bolus \\
\hline $\begin{array}{l}\text { Ljutic \& Rumboldt [38] } 1993 \\
\text { ESRD (9) }\end{array}$ & 25 & 10 & 2.5 & $1(11)$ & 0.76 & Glucose over 5 min then insulin bolus \\
\hline $\begin{array}{l}\text { Allon \& Shanklin [39] } 1996 \\
\text { ESRD (8) }\end{array}$ & 60 & 20 & 3 & $0(0)$ & 0.85 & $\begin{array}{l}\text { Insulin-glucose infusion at } 5 \mathrm{mU} / \mathrm{kg} / \mathrm{min} \\
\text { insulin for } 60 \mathrm{~min}\end{array}$ \\
\hline $\begin{array}{l}\text { Mahajan et al. [16] } 2001 \\
\text { ESRD (11) }\end{array}$ & 25 & 12 & 2.1 & $1(9)$ & 0.47 & $\begin{array}{l}\text { Insulin-glucose infusion at } 5 \mathrm{mU} / \mathrm{kg} / \mathrm{min} \\
\text { insulin for } 30 \mathrm{~min}\end{array}$ \\
\hline $\begin{array}{l}\text { Chothia et al., } 2014^{1} \\
\text { ESRD (10) }\end{array}$ & 50 & 10 & 5 & $2(20)$ & 0.83 & $\begin{array}{l}\text { Insulin-glucose over } 2-3 \mathrm{~min} \text { then glucose } \\
\text { over } 2-3 \mathrm{~min}\end{array}$ \\
\hline
\end{tabular}

Data were extracted from studies on the treatment of hyperkalemia with an insulin-glucose arm where data on hypoglycemia were reported. Dosages of insulin and glucose, and changes in plasma or serum $\left(\mathrm{K}^{+}\right)$are as at the end of $60 \mathrm{~min}$. The Glu/Ins ratio refers to the dose of glucose in grams and that of insulin in international units. AKI = Acute kidney injury; $\mathrm{CKD}=$ chronic kidney disease.

${ }^{1}$ Data from the present study.

centration which is comparable to that seen when insulin is administered.

Hypoglycemia remains a common complication of insulin therapy. In a recent Japanese hospital-based survey [37], hypoglycemia was associated with serious complications, including QT prolongation and new-onset atrial fibrillation. This, at least in part, might be related to the excessive release of sympathetic hormones in response to the hypoglycemia. In studies of insulin therapy for the treatment of hyperkalemia, hypoglycemia has been documented in as many as $75 \%$ of participants (table 2). There appear to be fewer hypoglycemic events when the glucose dose is larger, when the insulin bolus is given after the glucose infusion rather than before it and when the treatment is given as a constant infusion over $60 \mathrm{~min}$ rather than as a bolus. Careful clinical monitoring and repeated measurements of blood glucose are recommended for several hours after insulin therapy $[17,18]$.
Our protocol specified a higher glucose/insulin ratio (50 $\mathrm{g}$ of glucose/10 units of insulin) than those used in the other studies summarized in table 2 , but despite this there were hypoglycemic episodes in 2 of 10 patients. It is possible that giving the insulin after first infusing all of the glucose may have reduced the incidence of this complication.

The infusion of large amounts of hypertonic glucose without insulin carries the theoretical risk of increasing serum $\left[\mathrm{K}^{+}\right]$via the high serum osmolality, which may cause potassium-rich intracellular water to flow out of cells. In the study by Conte et al. [29], hypertonic saline caused an increase in serum $\left[\mathrm{K}^{+}\right]$independent of $\mathrm{pH}$, bicarbonate concentration, anion gap, insulin concentration and urinary adrenaline and noradrenaline levels. An earlier study by Goldfarb et al. [27] examined the effect of rapid infusions of hypertonic glucose on serum $\left[\mathrm{K}^{+}\right]$and found that hyperkalemia developed in subjects with combined insulin and aldosterone deficiency but not in normal volunteers or 
in diabetics with insulin deficiency alone. None of our participants had a rise in serum $\left[\mathrm{K}^{+}\right]$at 60 min compared to baseline values. At the earliest time point, when the effect of the hypertonic infusion would be expected to be maxi$\mathrm{mal}$, there were more patients in the insulin than in the glucose-only group with a rise in serum $\left[\mathrm{K}^{+}\right]$.

Another concern is that hypertonic solutions, with or without insulin, rapidly expand the extracellular fluid compartment, increasing the risk of pulmonary edema in patients with heart disease. This complication was seen in 1 of our participants after receiving the insulin-glucose combination.

The efficacy and safety of glucose-only boluses in treating hyperkalemia in acutely ill patients needs further investigation, and our data cannot be generalized to these patients. It is possible that in situations where $\alpha$-adrenergic stimulation might be increased, e.g. in critically ill patients, this would suppress endogenous pancreatic insulin release and a glucose-only regimen might not be effective in reducing serum $\left[\mathrm{K}^{+}\right]$.

\section{Conclusion}

In stable, nondiabetic HD patients an intravenous glucose bolus caused a clinically significant decrease in serum $\left[\mathrm{K}^{+}\right]$of $0.5 \mathrm{mmol} / 1$. This provides an additional treatment option in the emergency treatment of hyperkalemia without the risk of inducing hypoglycemia. Further studies are needed to investigate the role of this intervention in acutely ill patients.

\section{Acknowledgments}

We thank Vincent Boima and Jennifer Juta for their assistance with data collection, and Justin Harvey of the Stellenbosch University Center for Statistical Consultation for assistance with data analyses.

\section{Disclosures}

No conflicts of interest to report.

\section{References}

1 Acker CG, Johnson JP, Palevsky PM, Greenberg A: Hyperkalemia in hospitalized patients: causes, adequacy of treatment, and results of an attempt to improve physician compliance with published therapy guidelines. Arch Intern Med 1998;158:917-924.

2 Stevens MS, Dunlay RW: Hyperkalemia in hospitalized patients. Int Urol Nephrol 2000; 32:177-180.

3 Kamel KS, Wei C: Controversial issues in the treatment of hyperkalaemia. Nephrol Dial Transplant 2003;18:2215-2218.

4 Schwarz KC, Cohen BD, Lubash GD, Rubin AL: Severe acidosis and hyperpotassemia treated with sodium bicarbonate infusion. Circulation 1959;19:215-220.

5 Danowski TS, Greenman L, Mateer FM, Parsons WB, Weigand FA, Mermelstein $\mathrm{H}, \mathrm{Pe}-$ ters JH: Carboxylic cation exchange resin effects in dogs. J Clin Invest 1951;30:984-994.

6 Gruy-Kapral C, Emmett M, Santa Ana CA, Porter JL, Fordtran JS, Fine KD: Effect of single dose resin-cathartic therapy on serum potassium concentration in patients with end-stage renal disease. J Am Soc Nephrol 1998;9:1924-1930.

7 Lillemoe KD, Romolo JL, Hamilton SR, Pennington LR, Burdick JF, Williams GM: Intestinal necrosis due to sodium polystyrene (Kayexalate) in sorbitol enemas: clinical and experimental support for the hypothesis. Surgery 1987;101:267-272.

8 Gerstman BB, Kirkman P, Platt R: Intestinal necrosis associated with postoperative orally administered sodium polystyrene sulfonate in sorbitol. Am J Kidney Dis 1992;20:159-161.
9 McGowan CE, Saha S, Chu G, Resnick MB, Moss SF: Intestinal necrosis due to sodium polystyrene sulfonate (Kayexalate) in sorbitol. South Med J 2009;102:493-497.

10 Sterns RH, Rojas M, Bernstein P, Chennupati $S$ : Ion-exchange resins for the treatment of hyperkalemia: are they safe and effective? J Am Soc Nephrol 2010;21:733-735.

11 Kamel KS, Schreiber M: Asking the question again: are cation exchange resins effective for the treatment of hyperkalemia? Nephrol Dial Transplant 2012;27:4294-4297.

12 Rosić N, Standaert M, Pollet R: The mechanism of insulin stimulation of $\left(\mathrm{Na}^{+}, \mathrm{K}^{+}\right)$ATPase transport activity in muscle. J Biol Chem 1985;260:6206-6212.

13 Blumberg A, Weidmann P, Shaw S, Gnädinger M: Effect of various therapeutic approaches on plasma potassium and major regulating factors in terminal renal failure. Am J Med 1988;85:507-512.

14 Lens XM, Montoliu J, Cases A, Campistol JM, Revert L: Treatment of hyperkalemia in renal failure: salbutamol v. insulin. Nephrol Dial Transplant 1989;4:228-232.

15 Allon M, Copkney C: Albuterol and insulin for treatment of hyperkalemia in hemodialysis patients. Kidney Int 1990;38:869-872.

16 Mahajan S, Mangla M, Kishore K: Comparison of aminophylline and insulin-dextrose infusions in acute therapy of hyperkalemia in end-stage renal disease patients. J Assoc Physicians India 2001;49:1082-1085.
17 Williams PS, Davenport A, Bone JM: Hypoglycaemia following treatment of hyperkalaemia with insulin and dextrose. Postgrad Med J 1988;64:30-32.

18 Schafers S, Naunheim R, Vijayan A, Tobin G: Incidence of hypoglycemia following insulinbased acute stabilization of hyperkalemia treatment. J Hosp Med 2012;7:239-242.

19 Tarail R, Seldin DW, Goodyear AV: Effects of injection of hypertonic glucose on metabolism of water and electrolytes in patients with edema. J Clin Invest 1951;30:1111-1119.

20 Groen J, Willebrands AF, Kamminga CE, Van Schothorst HK, Godfried EG: Effects of glucose administration on the potassium and inorganic phosphate content of the blood serum and the electrocardiogram in normal individuals and in non-diabetic patients. Acta Med Scand 1952;141:352-366.

21 Marks PA, Bishop JS: The glucose metabolism of patients with malignant disease and of normal subjects as studied by means of an intravenous glucose tolerance test. J Clin Invest 1957;36:254-264.

22 Muto S, Sebata K, Watanabe H, Shoji F, Yamamoto Y, Ohashi M, Yamada T, Matsumoto H, Mukouyama T, Yonekura T, Namiki S, Kusano E: Effect of oral glucose administration on serum potassium concentration in hemodialysis patients. Am J Kidney Dis 2005;46: 697-705.

23 Evans KJ, Greenberg A: Hyperkalemia: a review. J Intensive Care Med 2005;20:272-290. 
24 Weisberg LS: Management of severe hyperkalemia. Crit Care Med 2008;36:3246-3251.

25 DeFronzo RA, Andres R, Edgar P, Walker WG: Carbohydrate metabolism in uremia: a review. Medicine (Baltimore) 1973;52:469481.

26 Porte DJ: Sympathetic regulation of insulin secretion. Arch Intern Med 1969;123:252-260.

27 Goldfarb S, Cox M, Singer I, Goldberg M: Acute hyperkalemia induced by hyperglycemia: hormonal mechanisms. Ann Intern Med 1976;84:426-432.

28 Ammon RA, May WS, Nightingale SD: Glucose-induced hyperkalemia with normal aldosterone levels. Studies in a patient with diabetes mellitus. Ann Intern Med 1978;89:349351.

29 Conte G, Dal Canton A, Imperatore P, De Nicola L, Gigliotti G, Pisanti N, Memoli B, Fuiano G, Esposito C, Andreucci VE: Acute increase in plasma osmolality as a cause of hyperkalemia in patients with renal failure. Kidney Int 1990;38:301-307.

30 DeFronzo RA, Alvestrand A, Smith D, Hendler R, Hendler E, Wahren J: Insulin resistance in uremia. J Clin Invest 1981;67:563-568.
31 Mak RH, DeFronzo RA: Glucose and insulin metabolism in uremia. Nephron 1992;61: 377-382.

32 Alvestrand A: Carbohydrate and insulin metabolism in renal failure. Kidney Int 1997; 62:S48-S52.

33 Alvestrand A, Wahren J, Smith D, DeFronzo RA: Insulin-mediated potassium uptake is normal in uremic and healthy subjects. Am J Physiol 1984;246:E174-E180.

34 Cheema-Dhadli S, Chong C-K, Kamel KS, Halperin ML: An acute infusion of lactic acid lowers the concentration of potassium in arterial plasma by inducing a shift of potassium into cells of the liver in fed rats. Nephron Physiol 2012;120:7-15.

35 Juel C, Halestrap AP: Lactate transport in skeletal muscle - role and regulation of the monocarboxylate transporter. J Physiol 1999; 517:633-642.

36 Counillon LL, Pouyssegur RJ: The members of the $\mathrm{Na}^{+} / \mathrm{H}^{+}$exchanger gene family: their structure, function, expression, and regulation; in Seldin DW, Giebisch G (eds): The Kidney: Physiology and Pathophysiology. Philadelphia, Lippincott Williams \& Wilkins, 2000, vol 1, pp 223-234.
37 Tsujimoto T, Yamamoto-Honda R, Kajio $\mathrm{H}$ Kishimoto M, Noto H, Hachiya R, Kimura A, Kakei M, Noda M: Vital signs, QT prolongation, and newly diagnosed cardiovascular disease during severe hypoglycemia in type 1 and type 2 diabetic patients. Diabetes Care 2014; 37:217-225.

38 Ljutic D, Rumboldt Z: Should glucose be administered before, with, or after insulin, in the management of hyperkalemia? Ren Fail 1993. 15:73-76

39 Allon M, Shanklin N: Effect of bicarbonate administration on plasma potassium in dialysis patients: interactions with insulin and albuterol. Am J Kidney Dis 1996;28:508514.

40 Kim HJ: Combined effect of bicarbonate and insulin with glucose in acute therapy of hyperkalemia in end-stage renal disease patients. Nephron 1996;72:476-482.

41 Ngugi N, McLigeyo S, Kayima J: Treatment of hyperkalaemia by altering the transcellular gradient in patients with renal failure: effect of various therapeutic approaches. East Afr Med J 1997;74:503. 